Viewpoint

\title{
Risk assessment of GM stacked events obtained from
} crosses between

\section{GM events}

\section{A. De Schrijver ${ }^{a, *}$, Y. Devos ${ }^{b}$, M. Van den Bulcke ${ }^{\mathrm{a}}$, P. $\operatorname{Cadot}^{\mathrm{c}}$, M. De Loose ${ }^{d}$, D. Reheul ${ }^{b}$ and M. Sneyers ${ }^{\mathrm{a}}$}

\begin{abstract}
aDivision of Biosafety and Biotechnology, Scientific Institute of Public Health, Juliette Wytsmanstraat 14, 1050 Brussels, Belgium (Tel.: + 322642 5293; fax: + 322642 5292; e-mail: ads@sbb.ihe.be)

${ }^{b}$ Department of Plant Production, Faculty of Bioscience Engineering, University of Ghent, Coupure Links 653, 9000 Ghent, Belgium

cDepartment of Clinical Immunology, Catholic University of Leuven, $\mathbf{3 0 0 0}$ Leuven, Belgium

${ }^{\mathrm{d} D e p a r t m e n t}$ of Technology and Food, Institute for Agricultural and Fisheries Research, 9820 Merelbeke, Belgium
\end{abstract}

The risk assessment of GM stacked events, which are considered as a new GMO in the EU, could be less extensive than the assessment of the parental GM events. This will be the case when the latter have been proven to be safe for the human health and the environment for the same uses as the GM stacked event. Criteria for the risk assessment of GM stacked events combining positively assessed GM parental lines are proposed. Molecular and comparative analysis data are put forward as minimum requirements. Additional food/ feed safety testing and environmental studies are considered relevant on a case-by-case basis.

\section{* Corresponding author.}

0924-2244/\$ - see front matter (C) 2006 Elsevier Ltd. All rights reserved. doi:10.1016/j.tifs.2006.09.002

\section{Introduction}

The commercial introduction of genetically modified (GM) crops is no longer a hypothetical fact in the European Union (EU). Since the lifting of the de facto moratorium in 2004, a number of new GM events have been authorised for food, feed, import and/or processing. Moreover, the cultivation of GM maize is gradually increasing as a result of the inscription of various transgenic maize varieties in the common EU catalogue of varieties of agricultural plant species (for review see Devos, Reheul, \& De Schrijver, 2005). Until recently, the dossiers handed in for market authorisation solely covered single GM events. Nowadays, there is a clear trend to combine two or more transgenic traits present in single events through traditional breeding. This is in particular the case for maize events due to the hybrid tradition in the crop (Table 1). The obtained plants are referred to as GM stacked events.

According to current regulatory practice within the EU, stacked events are considered as new GMOs: prior to marketing they need regulatory approval, including an assessment of their safety, similar to single events. In other nations, like the United States, this may not be obligatory (e.g. Kuiper, Kleter, Noteborn, \& Kok, 2001). An interesting example of the regulatory requirements for assessment of a GM stacked event derived from previously assessed single events is MON810 $\times$ MON863 maize from Monsanto, which was approved under Directive 2001/18/EC for commercialisation on 13 January 2006 (EC, 2006). In the procedure leading to the positive opinion on MON810 $\times$ MON863, the Scientific Panel of the European Food Safety Authority (EFSA) involved in the evaluation of genetically modified organisms (GMOs) requested confirmatory data next to the various data that it had already received on this stacked event. The additional data consisted of a 90-day rat toxicity feeding study in order to finalise the assessment (EFSA, 2005a). Interestingly, upon publication of the EFSA opinion on MON810 $\times$ MON863, the British Advisory Committee on Release to the Environment (ACRE) issued a contrasting statement that no additional information is needed for the risk assessment of GM stacked events. This Committee considered that the confirmation of the safety profile of the two parent lines is sufficient to support a positive assessment of a GM stacked event that has been produced by conventional breeding (ACRE, 2004). The risk assessment of GM stacked events has been put on the agenda of several (inter)national fora (e.g. EFSA, 2006a; FAO/WHO, 2006; FIFRA, 2004). This gives 


\begin{tabular}{|c|c|c|c|}
\hline \multicolumn{4}{|l|}{ Cotton } \\
\hline $\begin{array}{l}\text { Notified stacked } \\
\text { cotton events }\end{array}$ & Commercial uses & Single cotton events & $\begin{array}{l}\text { Approved or positively } \\
\text { assessed commercial uses }\end{array}$ \\
\hline MON531 × MON1445 & $\mathrm{FO}, \mathrm{FE}$ & $\begin{array}{l}\text { MON531 } \\
\text { MON1445 }\end{array}$ & $\begin{array}{l}\text { FO- } \\
\text { FO- }\end{array}$ \\
\hline MON15985, MON15985 × MON1445 & $\mathrm{FO}, \mathrm{FE}$ & $\begin{array}{l}\text { MON15985 } \\
\text { MON1445 }\end{array}$ & - \\
\hline $281-24-236 \times 3006-210-23$ & $\mathrm{FO}, \mathrm{FE}$ & $\begin{array}{l}281-24-236 \\
3006-210-23\end{array}$ & - \\
\hline LLcotton25 × MON15985 & $\mathrm{FO}, \mathrm{FE}$ & $\begin{array}{l}\text { LLcotton25 } \\
\text { MON15985 }\end{array}$ & $\begin{array}{l}- \\
-\end{array}$ \\
\hline \multicolumn{4}{|l|}{ Maize } \\
\hline $\begin{array}{l}\text { Positively assessed } \\
\text { stacked maize events }\end{array}$ & Commercial uses & Single maize events & $\begin{array}{l}\text { Approved or positively } \\
\text { assessed commercial uses }\end{array}$ \\
\hline MON863 × MON810 & $\mathrm{FO}, \mathrm{FE}$ & $\begin{array}{l}\text { MON863 } \\
\text { MON810 }\end{array}$ & $\begin{array}{l}\text { FO, FE, IM, IP } \\
\text { FO-, FE, IM, IP, CU }\end{array}$ \\
\hline MON863 × NK603 & FO, FE, IM, IP & $\begin{array}{l}\text { MON863 } \\
\text { NK603 }\end{array}$ & $\begin{array}{l}\text { FO, FE, IM, IP } \\
F O, F E, I M, I P\end{array}$ \\
\hline MON863 × MON810 × NK603 & FO, FE, IM, IP & $\begin{array}{l}\text { MON863 } \\
\text { MON810 } \\
\text { NK603 } \\
\text { MON863 } \times \text { MON810 }\end{array}$ & $\begin{array}{l}\text { FO, FE, IM, IP } \\
\text { FO-, FE, IM, IP, CU } \\
\text { FO, FE, IM, IP } \\
\text { IM, IP }\end{array}$ \\
\hline NK603 $\times$ MON810 & FO, FE, IM, IP & $\begin{array}{l}\text { NK603 } \\
\text { MON810 }\end{array}$ & $\begin{array}{l}\text { FO, FE, IM, IP } \\
\text { FO-, FE, IM, IP, CU }\end{array}$ \\
\hline $1507 \times$ NK603 & FO, FE, IM, IP & $\begin{array}{l}1507 \\
\text { NK603 } \\
\end{array}$ & $\begin{array}{l}\mathrm{FO}, \mathrm{FE}, \mathrm{IM}, \mathrm{IP}, \mathrm{CU}^{\mathrm{a}} \\
\mathrm{FO}, \mathrm{FE}, \mathrm{IM}, \mathrm{IP}\end{array}$ \\
\hline $\begin{array}{l}\text { Notified stacked } \\
\text { maize events }\end{array}$ & Commercial uses & Single maize events & $\begin{array}{l}\text { Approved or positively } \\
\text { assessed commercial uses }\end{array}$ \\
\hline $1507 \times 59122$ & $\mathrm{FO}, \mathrm{FE}, \mathrm{IM}, \mathrm{IP}, \mathrm{CU}$ & $\begin{array}{l}1507 \\
59122\end{array}$ & $\begin{array}{l}\mathrm{FO}, \mathrm{FE}, \mathrm{IM}, \mathrm{IP}, \mathrm{CU}^{\mathrm{a}} \\
-\end{array}$ \\
\hline $1507 \times$ NK603 & $\mathrm{CU}$ & $\begin{array}{l}1507 \\
\text { NK603 } \\
1507 \times \text { NK603 }\end{array}$ & $\begin{array}{l}\mathrm{FO}, \mathrm{FE}, \mathrm{IM}, \mathrm{IP}, \mathrm{CU}^{\mathrm{a}} \\
\mathrm{FO}, \mathrm{FE}, \mathrm{IM}, \mathrm{IP}^{\mathrm{P}} \\
\mathrm{FO}^{\mathrm{a}}, \mathrm{FE}^{\mathrm{a}}, \mathrm{IM}^{\mathrm{a}}, \mathrm{IP}^{\mathrm{a}}\end{array}$ \\
\hline NK603 × MON810 & $\mathrm{CU}$ & $\begin{array}{l}\text { NK603 } \\
\text { MON810 } \\
\text { NK603 } \times \text { MON810 }\end{array}$ & $\begin{array}{l}\mathrm{FO}, \mathrm{FE}, \mathrm{IM}, \mathrm{IP} \\
\mathrm{FO}-, \mathrm{FE}, \mathrm{IM}, \mathrm{IP}, \mathrm{CU} \\
\mathrm{FO}^{\mathrm{a}}, \mathrm{FE}^{\mathrm{a}}, \mathrm{IM}^{\mathrm{a}}, \mathrm{IP}^{\mathrm{a}}\end{array}$ \\
\hline $1507 \times 59122$ & $\mathrm{FO}, \mathrm{FE}, \mathrm{IM}, \mathrm{IP}, \mathrm{CU}$ & $\begin{array}{l}1507 \\
\text { DAS-59122-7 }\end{array}$ & $\begin{array}{l}\mathrm{FO}, \mathrm{FE}, \mathrm{IM}, \mathrm{IP}, \mathrm{CU}^{\mathrm{a}} \\
-\end{array}$ \\
\hline DAS-59122-7 × NK603 & $\mathrm{FO}, \mathrm{FE}, \mathrm{IM}, \mathrm{IP}, \mathrm{CU}$ & $\begin{array}{l}\text { DAS-59122-7 } \\
\text { NK603 }\end{array}$ & $\overline{F O}, F E, I M, I P$ \\
\hline DAS-59122-7 × 1507 × NK603 & $F O, F E, I M, I P, C U$ & $\begin{array}{l}\text { DAS-59122-7 } \\
1507 \\
\text { NK603 }\end{array}$ & $\begin{array}{l}- \\
\text { FO, FE, IM, IP, } C U^{a} \\
F O, F E, I M, I P\end{array}$ \\
\hline LY038 × MON810 & FO, FE, IM, IP & $\begin{array}{l}\text { LY038 } \\
\text { MON810 }\end{array}$ & $\overline{\mathrm{FO}}-\overline{\mathrm{F}}, \mathrm{IM}, \mathrm{IP}, \mathrm{CU}$ \\
\hline MON88017 × MON810 & FO, FE, IM, IP & $\begin{array}{l}\text { MON88017 } \\
\text { MON810 }\end{array}$ & $\overline{F O}-$, FE, IM, IP, CU \\
\hline \multicolumn{4}{|l|}{ Oilseed rape } \\
\hline $\begin{array}{l}\text { Positively assessed } \\
\text { stacked oilseed rape events }\end{array}$ & Commercial uses & $\begin{array}{l}\text { Single oilseed } \\
\text { rape events }\end{array}$ & $\begin{array}{l}\text { Approved or positively } \\
\text { assessed commercial uses }\end{array}$ \\
\hline MS1, RF1, MS1 $\times$ RF1 & FO-, CU & $\begin{array}{l}\text { MS1 } \\
\text { RF1 }\end{array}$ & $\begin{array}{l}\text { FO-, CU } \\
\text { FO-, CU }\end{array}$ \\
\hline MS8, RF3, MS8 $\times$ RF3 & FO-, IM, IP & $\begin{array}{l}\text { MS8 } \\
\text { RF3 }\end{array}$ & $\begin{array}{l}\text { FO-, IM, IP } \\
\text { FO-, IM, IP }\end{array}$ \\
\hline \multicolumn{4}{|c|}{$\begin{array}{l}\text { Belgian Biosafety Server: http://www.biosafety.be; European Commission: http://europa.eu.int/comm/food/food/biotechnology/index_en.htm; } \\
\text { European Food Safety Authority: http://www.efsa.europa.eu } \\
\text { Abbreviations: FO=food (all products); FO- = food (only derivatives); FE = feed; IM=import; IP=industrial processing; } C U=\text { cultivation. } \\
\text { a Positively assessed events by EFSA. }\end{array}$} \\
\hline
\end{tabular}


further support to the notion that while the current safety assessment of GM crops for food, feed and environmental applications is rigorous, it would merit from harmonisation of the requirements for stacked events.

Information on how GM stacked events should be assessed is rare. Only the industry platform, EuropaBio has published a document on the evaluation of GM stacked events (EuropaBio, 2005) formulating some guidelines for risk assessment. Scientific argumentation as to why information is asked for risk assessment is even scarcer. The objective of this paper is (1) to review and discuss the risk assessment of environmental, animal and human safety aspects related to stacks obtained from the crossing of GMOs and (2) to provide some guidance on how risk assessment of GM stacked events might be performed. Gaps in knowledge are identified.

\section{Defining GM stacked events}

Often reference is made to 'stacked products', 'stacked events', 'breeding stacks', 'stacked genes' or 'pyramided traits', when talking about GM crops obtained through conventional cross breeding. In the OECD guidance document on the designation of a unique identifier for transgenic plants (OECD, 2002), stacked transformation events are defined as new products with more than one transformation event. For the purpose of this paper, the OECD definition remains too broad. According to the logic of the OECD definition, a stacked transformation event could be a re-transformation of an existing transgenic line or a cross between two GM transgenic lines (for more information on how to obtain stacks see Halpin, 2005). As the risk assessment of re-transformed events will follow the scenario of a single GM event, these do not fall under the events considered in the current paper. Here, solely plants obtained from crosses of GM events are considered when speaking of GM stacked events.

Also the terms GM hybrids and GM stacked events should not be confused. In case of GM hybrids, the transgenic trait originates from the GM inbred parental line that was crossed with one (or more) non-transgenic elite inbred line(s). In case of GM stacked events two or more transgenic traits are brought together by crossing GM inbred lines each transformed with different events (Fig. 1). One-way GM stacked events, where two transgenic traits are combined, and three-way GM stacked events, where three transgenic traits are combined, have been notified for authorisation in the EU (Table 1). GM stacked events combining more than three transgenic traits can be expected. GM hybrid lines derived from an approved GM event are covered within the scope of EU market consents implicating that their safety has been assessed.

\section{Risk assessment of GM stacked events}

Though GM stacked events should be evaluated in the EU for their risks for the environment and animal/human

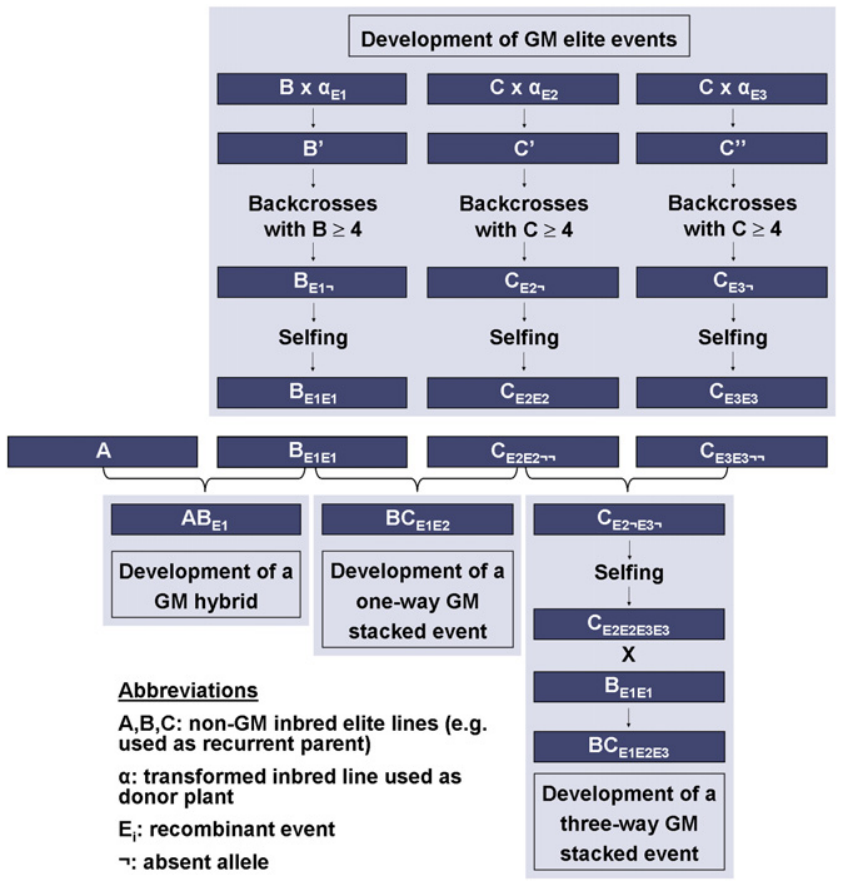

Fig. 1. Successive steps in the development of GM hybrids and GM stacked events.

health, the question remains how this should be done and which data are needed. When discussing this topic, one should keep in mind that for any GMO to be deliberately released in the environment, according to EU legislation, the risk assessment should include information on environmental aspects (EC, 2001). In case the GM crop will be used for animal (feed) or human nutrition (food), the risk assessment should contain additional information on toxicological, allergenic and nutritional food/feed aspects (EC, 2003a).

When taking a closer look at the dossiers notified under the EU GMO legislation, one can classify the GM stacked events into two different subgroups each posing their specific risk assessment challenges (Table 1). One group of GM stacks comprising GM events that have already been proven to be safe for the same uses as the GM stacked event, a second group of which at least one GM event has not been proven to be safe for the same use as the GM stack. A GM event is considered to be safe in case an authorisation for marketing in the EU has been granted or in case a favourable scientific EFSA opinion has been published (for risk assessment criteria see EFSA, 2004).

The risk assessment of GM stacked events combining positively assessed single GM events could logically start from the risk assessment performed on the GM parental lines. However, proof might be needed in order to be able to extrapolate the risk assessment studies done on the parental GMOs to the GM stacked event. 
Several stacked GM maize events combining positively assessed single GM maize events and a GM oilseed rape stacked event have already been evaluated for their risks for the environment and human/animal health in the $\mathrm{EU}$ (EFSA, 2005a, 2005b, 2005c, 2005d, 2005e, 2005f, $2005 \mathrm{~g}, 2006 \mathrm{~b})$. In the scientific risk evaluations carried out by the EFSA, assessment data for the single GM events were taken into account, besides the data provided by the notifier for the evaluation of the GM stacked events. All dossiers contained genotypic data, usually a Southern blot, to demonstrate that the molecular structures of the DNA inserts of the GM stacked events were unchanged and data on the expression levels of the traits in the GM stacked events. Comparative data, including agronomic performance, compositional analysis and wholesomeness studies using broiler chickens or rabbits were provided for the GM stacked events. A 90-day rat toxicity study was provided or requested, except for $\mathrm{MS} 8 \times \mathrm{RF} 3$ (EFSA, 2005e), NK603 $\times$ MON810 (EFSA, 2005f) and $1507 \times$ NK603 (EFSA, 2006b), to assess the whole food/feed toxicology of the GM stacked event. In those three particular cases, it was concluded that the information already provided for the assessment of the GM stacked event was sufficient to prove the safety of the whole food/feed. No additional information was considered necessary for the evaluation of possible increased allergenicity of the whole GM stacked crops, since neither maize nor oilseed rape is considered as a common allergic food.

In the present paper, it is explored which studies performed on the GM parental lines could remain valid for the evaluation of a GM stacked event and what type of information is needed to extrapolate the risk assessment data of the parental GM lines to the GM stacked event. Also whether additional information is needed to allow a thorough risk assessment of the GM stacked event is discussed. We have tried to develop a GM stack holistic risk assessment approach starting from the identification of the molecular data of the GM stacked event required to evaluate various safety aspects. As a case study, a GM stack obtained by the crossing of two GM events is taken. Obviously, the same reasoning is applicable for the evaluation of three-way GM stacked events or GM stacked events combining more than three transgenic traits. Every safety evaluation aspect, including environmental and food/feed aspects needed to prove the biosafety of the GMO will be discussed in detail.

\section{Molecular characterisation}

When commencing a risk assessment of a GM crop, one needs to be certain that the event under evaluation contains the desired characteristics. Therefore, for single GM events, data are provided on the actually inserted sequences. Merely as a means of confirmation of the presence of the transgenic characteristics in the GM stacked event, their inheritance should be documented. Taken into consideration that for all authorised single GM events, Southern blot analyses are used to prove correct transfer to different genetic backgrounds by conventional breeding, this type of genotypic analysis could provide the necessary basic molecular information on the GM stacked event.

In the following chapters on risk assessment issues, it is documented that besides the presence of the trait(s), it is also relevant to demonstrate the maintenance of the regions flanking the insert, since this will allow extrapolation of the bio-informatic analysis carried out on the junction regions of the single GM events. Bio-informatic analyses are conducted to identify potential chimaeric open reading frames (ORFs) in the junction regions of the insert. Given this, one can consider to not only confirm the maintenance of the transgenic traits of the GM stacked event via Southern blot analysis, but also of the regions flanking the inserts.

Southern blot analysis of the GM stacked event can confirm the maintenance of the transgenic inserts of the GM parental lines, comprising their copy number and structure. It will, however, only confirm the gross structure of the inserts; point mutations, small deletions and rearrangements that might occur during breeding will not be detected. Only via sequencing these can be visualised. Several issues should be taken into account when considering if sequence information is needed for the evaluation of GM stacked events. There is a common saying that transgenic DNA inserts (including the flanking regions) remain unchanged during breeding. However, hardly any, if none, scientific evidence proving that (trans)genes are inherited in an intact way during breeding is publicly available. In particular, information on the occurrence of point mutations, deletions and/or rearrangements during breeding is lacking. Only in case of the Bt11 event, it has been proven at sequence level that no genetic rearrangement or deletion in insert or flanking regions has occurred when crossing the inbred Bt11 field maize with an elite sweet maize cultivar (BAC, 2004). On the other hand, there is also no scientific argument to say that transgene inserts would behave differently than endogenous sequences in function of mutation rate. Given the absence of scientific proof, one can question the need or necessity of asking sequence data. However, the question of importance for biosafety assessment is whether structural modifications of the insert not detected through Southern blot and that might occur during traditional breeding will impose any risk. For example, a rearrangement might lead to the formation of a new ORF; a deletion, might result in an inactive protein; a point mutation might influence the characteristics of the expressed protein. The true impact of 'small' insertional changes on the intrinsic characteristics of the crop will, however, not be completely resolved through sequence analysis followed by bio-informatic analysis (e.g. small deletions of a gene might still result in an active protein). As expression levels of the 
traits, comparative compositional analysis and the safety evaluation of the whole food/feed, will reveal more on the impact of potential 'small' molecular changes that might occur during interbreeding of GM events than sequence analysis, the latter might be considered irrelevant to ask.

A second identified requirement for data extrapolation is the knowledge of the transgene expression levels in the GM stacked event. Transgene expression may change when a transgene is placed in a different genetic background through breeding. In addition, one should take into consideration that in the case of GM stacked events, the combined presence of transgenes might influence expression. For example, gene silencing that involves transgene/transgene interactions might occur in case homologous DNA sequences, e.g. expression controlling elements, are brought together (Fagard \& Vaucheret, 2000). Therefore, it will be relevant to determine if transgene expression has changed in the GM stacked event compared to the single event.

An additional molecular aspect that is considered in the evaluation of GM crops, is the stability of the inserts over several generations. However, when determining whether this information is needed, one should take into consideration that during breeding only hybrids with stable inserts are retained to produce hybrid-sowing seed. In addition, as the hybrid crop $\left(\mathrm{F}_{1}\right)$ or grains produced on the hybrid crop $\left(\mathrm{F}_{2}\right)$ will be harvested and processed, information on the stability of the insert will not necessarily add to the risk safety assessment of the GM stacked event. Only if part of the $F_{2}$ progeny will be used for cultivation or the GM stack will be used for GM hybrid maize production, data on the stability of the insert over several generations will be relevant, given the prolonged environmental exposure. The use of $F_{2}$ seed is, however, not a common agricultural practice in the EU.

\section{Comparative analysis}

An important issue to be evaluated, is whether the agronomic and morphological characteristics, and composition of the GM stacked event remain the same compared to the traditionally grown crop or the single GM events. Comparative analysis might identify unintended effects resulting from the interbreeding of GM varieties (e.g. synergistic or antagonistic interactions of the transgenic proteins). If statistically significant differences are found with the comparator, the impact of these changes should be further assessed to determine their biological significance.

Agronomic, phenotypic and compositional data are generally collected from field trials carried out in a range of agricultural environments that are typical of the place where the crop is grown. Agronomic performance studies include evaluations of plant vigour, growth habit, yield, crop quality, and insect and disease susceptibility.
EuropaBio considers data collected from four sites over a single growing season sufficient to allow a thorough analysis (EuropaBio, 2005). Commonly, the non-GM equivalent is used as the appropriate comparator in the comparative analysis studies given that the genetic background is comparable (EFSA, 2004). In the case of GM stacked events, however, the single event might also serve as a good comparator.

\section{Environmental aspects}

The environmental risk assessment of a GM crop is based on the recipient, the genetic modification, the GMO, the intended release or use, the potential receiving environment and the interaction between these (EC, 2002). The environmental risk assessment data on the recipient, the genetic modification and the potential receiving environment of the single GM events will remain valid for the GM stacked event. Since the GM stacked event is considered as a new GMO, aspects linked to the GM crop that might alter its interactions with the environment will be relevant to take into consideration during risk assessment.

A change in the level of expression of the introduced proteins in the GM stacked event compared to the GM parental line might on a case-by-case basis affect the agro-ecosystem. Higher levels of transgene expression might result in unintended adverse effects on non-target organisms; lower levels might lead to increased risk for insect-resistance of target organisms. If it has been shown on the basis of the molecular studies that the level of expression of the single GM event corresponds to that of the GM stacked event, data proving the environmental safety of the single GM event can be passed on to the GM stacked event. In case the expression level of an introduced/modified trait in the GM stacked event falls outside the range of the one determined in the GM parental line, a re-evaluation of the environmental aspects might be necessary, if considered relevant (depending on the trait). It must be noted that whether an assessment of the environmental aspects is needed or not, will not only depend on the transgenic trait considered, but also on the intended release or use of the GM stacked event. Only in this case the GM stacked event is released for cultivation, data on the expression level of the new proteins will be needed in order to determine if the effect of the GM crop on the environment will remain the same compared to the single GM events.

In GM stacked events, several traits - currently limited to insect and herbicide resistance in the EU applications are brought together. Special attention should be given to GM stacks that combine events with transgene protein products that have a similar and potentially synergetic type of mode of action. The combined presence of two toxins might result in a changed effect on target and nontarget organisms, or lead to cross-resistance. Unless there is an indication that proteins would interact, such as being 
parts of a binary toxin or attaching to the same receptor, there is little to justify testing the combined effect of the toxins. The notified stacked events that need attention for the moment are those combining Bacillus thuringiensis (Bt) toxins. Bt insecticidal proteins are toxic due to their action as pore formers in insect gut mediated through specific binding to membrane proteins. As different Bt toxins share specific binding sites (Estela, Escriche, \& Ferre, 2004; Hua, Masson, Jurat-Fuentes, Schwab, \& Adang, 2001; Li et al., 2004; Schnepf et al., 1998), synergetic (non-)target effects and cross-resistance mediated by changes in receptors can be envisaged.

The presence of multiple resistance traits can also provide a selective advantage (Snow et al., 2003), by which the persistence and invasiveness of the crop or sexually compatible relatives could be enhanced (Chapman \& Burke, 2006). Moreover, multiple resistance traits in combination with novel agricultural practices might lead to changes in farmland biodiversity (Ammann, 2005).

In case of cultivation and depending on the crop and traits, on the one hand, field experimentation with the GM stacked event might be considered before commercialisation. On the other hand, post-market monitoring could be envisaged to study the potential adverse agroecological effects of the cultivation of GM stacked events.

Toxicology and allergenicity testing: protein safety evaluation

When testing newly expressed proteins - be it the intended traits or the unintendedly expressed proteins - of a GM crop for their toxicology and allergenicity aspects, it is recommended, as a first step in the assessment to conduct bio-informatic analyses on the inserted transgenic DNA. This will allow comparison of the transgenic protein(s) with those of allergenic and toxic proteins (EFSA, 2004). If correctly conducted, bio-informatic analyses will give a first indication of the toxic and allergenic potential of the proteins expressed by the inserted transgenic DNA. Consequently, in vitro tests investigating the biological toxic potential and the potential of the newly expressed proteins to elicit allergic reactions more into detail are carried out. By feeding purified proteins to test animals, the toxicology potential of the newly expressed proteins is often further evaluated in vivo.

When considering which toxicity and allergenicity studies done on the single GM events remain valid for the GM stacked event and in particular the conditions under which they remain valid, one falls back on the molecular characterisation studies. If during crossing, the insert and the flanking regions of the GM parental events are transmitted intactly to the GM stacked event, the bio-informatic analyses done on the GM parental inbred lines to identify the toxic and/or allergenic potential of any newly produced protein will remain valid for the GM stacked event.
Obviously, also the in vitro investigations and the oral toxicity studies done with purified target proteins will remain valid for the GM stacked event. In other words, if it has been demonstrated that the inserts and junction regions are maintained and that the introduced traits or newly expressed chimaeric proteins present in the single events will not act as allergens or toxins in the GM parental inbred lines, it is not relevant to demonstrate this again in the GM stacked event.

Toxicology and allergenicity testing: testing of whole GM food/feed or crop

Risk assessment of the whole GM plant must consider whether allergenicity or toxicity of the crop could be increased. This is particularly important when the non-GM host plant is known as an allergen or toxin source. Toxicity testing most often includes a 90-day toxicity study in rodents; allergenicity testing is done by comparison of the allergen repertoire of the GM crop with that of the conventional non-GM variety.

When considering the extrapolation of whole GM food/ feed toxicology studies, one should take into account that in the GM stacked event the expression level of the introduced traits might be different from that of the GM parental lines. One can postulate that an increase in the amount of newly expressed protein could lead to a toxic effect if the protein is potentially toxic. The level of expression of the newly introduced trait in the GM stacked event will, however, have to be compared to the levels at which this protein exerts toxic effects in toxicity tests, i.e. the so-called margin of safety $(\mathrm{MoS})$. If the MoS is large for the GM parental line, it can be envisioned that the expression in the stacked event needs to be much higher than the level of expression determined in the GM parental inbred line to cause a toxic effect. In summary, one can say that the information on the expression level of the newly introduced traits in the GM stacked event is relevant with regard to the possible need for whole GM food/feed toxicology studies of the GM stacked event. However, it should be realised that such whole food testing experiments have their limitations, due to limited dose range and complexity of the product (e.g. Kuiper et al., 2001).

Another aspect that is of concern when considering the extrapolation of the whole GM crop or food/feed toxicology and allergenicity studies carried out with single GM events to the GM stacked event, are the potential interactions of the newly introduced genes, regulatory sequences and proteins (or its metabolites) with the host genome of the GM stacked event. Given that the transgenic DNA sequences/proteins are brought into a different genetic background, namely the stacked genetic background, their interaction with the genome might change, particularly if regulatory proteins, such as in experimental stress-resistant crops described in literature, are involved. Interactions with the genome might lead to a change in overall toxicity 
and/or allergenicity of the GM stacked event, if the host plant is known to be allergenic or toxic in its own right. One should take into account that there are no tests available to predict if interactions of the newly introduced DNA sequences/proteins at cellular level will occur. Indirect evidence has to be obtained from extensive analysis of compositional, phenotypic and agronomic characteristics. Whether the natural amount of toxins has changed, can be revealed by compositional analysis. If uncertainty remains or if differences are indeed confirmed, overall toxicity testing of the GM stacked event may be considered. As discussed above, animal toxicity testing with whole food has its limitations, for example with regard to sensitivity, and may not be able to pick up subtle differences that are detected by compositional analysis (e.g. Chassy et al., 2004; Kuiper et al., 2001). Whether the natural amount of allergens has been changed can be revealed by comparing the allergen repertoire between the non-GM and the GM stacked event. Although, different in vitro methods are available for that purpose, some of them using patients' sera, they are not all well-validated methods.

Last but not least, toxins individually considered safe might lead to unacceptable health effects when exposure is to a combination. Only in case synergistic toxic effects are expected (e.g. toxins with common health effect), it will be relevant to demand additional toxicity studies, the exact nature of which will depend on the data available and the characteristics of the modified crops, transgenes, and anticipated effects.

\section{Nutritional food/feed assessment}

In the evaluation of the nutritional aspects of a single GM event, the raw agricultural commodities and, on a case-bycase basis, the processed fractions, are assessed for key nutrients as well as naturally occurring anti-nutrients, toxicants and secondary plant metabolites (EFSA, 2004). Once compositional equivalence, except for the introduced traits, has been established between a GM food or feed with its conventional counterpart, nutritional equivalence can be assumed (Clark \& Ipharraguerre, 2001). Further nutritional analysis, including animal performance, feed and digestion studies could be done; however, such studies should be considered on a case-by-case basis (Kuiper et al., 2001).

Compositional analyses carried out on parental GM events combined in a stack cannot be extrapolated per se to the stacked event. Through hybrid breeding the composition of a crop might change. Interactions of transgenes and the newly expressed proteins might result in effects on biochemical pathways (Pinçon et al., 2001). Therefore, compositional analysis of the GM stacked event is relevant for risk assessment to identify if any possible adverse effects might result from a change in composition. Animal feeding trials are an additional tool to establish nutritional equivalence and to test the nutritional properties of the GM stacked event product.

\section{Conclusions}

In this article the risk assessment of GM stacked events, defined as plants obtained from the crossing of GM events, is discussed in order to provide some guidance for their assessment. Whether data are needed at all for risk assessment of GM stacked events, has been argued by ACRE (ACRE, 2004). Objections to accept certain criteria for the risk assessment of GM stacked events might be the result of the fact that no legislation at European level depicts that non-GM hybrids should be tested for their safety for the environment and human/animal health. If non-GM hybrids need no testing, why should this then be done for GM stacked events? In addition, the fact that from a legal point of view it remains vague whether GM stacked events should be evaluated, could add to the restraint to ask for safety assessment data. Nowhere in EU legislation is it clearly stated that a hybrid obtained through the crossing of two GMOs is considered as a new GMO and therefore should be evaluated for its risks for the environment and human/animal health. This vagueness can lead to individual interpretations of the legislation. However, as the European Commission considers a GM stacked event as a new GMO (EC, personal communication), risk assessment data should be provided as part of the approval process (EC, 2003b; EFSA, 2004).

When reflecting on the risk assessments of GM stacked events, it becomes clear that these could be less exhaustive compared to the risk assessments of single GM events when the GM parental lines have already been positively assessed for their biosafety. In the present paper, it is shown that the safety assessments of the parental GM events form a good basis for the evaluation of GM stacked events taking into account that all uses of the GM stacked event under evaluation are covered in the assessed parental GM lines. However, additional information proving the validity of the studies carried out on the GM parental lines for the GM stacked event will be needed to complete the risk assessment together with data proving the biosafety of the GM stacked event. In case one or more GM parental lines have not been evaluated under EU legislation, one can choose to carry out a complete risk assessment on the non-assessed GM parental line(s) or on the GM stacked event. The risk assessment of the GM stack should, however, also include an evaluation of single events as the offspring, which are segregating plants, will be used for consumption.

Minimum requirements identified in order to be able to extrapolate data obtained with the parental GM lines to the GM stacked event are: (1) evidence of the presence and the copy number of the parental inserts (including the flanking regions) in the GM stacked event and (2) evidence that the levels of expression of the newly 
expressed proteins in the GM stack equal to that of the GM parental lines. Proof that the insert is conserved during the breeding process, is needed to consider the studies on protein and food/feed safety conducted on the GM parental lines as valid for the risk evaluation of the GM stacked event. Solely if the insert is conserved in the GM stacked event, and consequently also the characteristics of the transgenic protein, studies done to test the safety of the new proteins in the single GM events will also apply for the stack. Logically, food/feed safety data linked to the insert will only apply both for the single GM and the stacked event in the case of molecular equivalence at insert and protein level. In case of cultivation, and depending on the traits considered, information on expression level is also needed to be able to extrapolate environmental biosafety studies carried out with the parental GM lines to the GM stacked event.

As in GM stacked events several traits are combined, it is recommended to at least carry out agronomic, morphological and compositional studies on the GM stacked event in order to identify potential adverse effects that might result from interbreeding of GM cultivars. These studies will reveal if the phenotype and the composition, including the amount of naturally occurring allergens and toxins, of the GM stacked event will be equivalent to its comparators. If changes have been detected, their impact will need to be further assessed. Further testing of the potential adverse effects of the combined presence of traits needs to be considered on a case-by-case basis. If compounds with a synergistic toxic potential for animals and/or humans are combined in the GM stacked event, additional toxicity testing is considered relevant. Additional environmental studies and/or post-market monitoring will be relevant if, for instance, there is an increased risk of invasiveness, synergistic toxic effects on non-target organisms or cross-resistance due to the combined presence of several traits.

Several safety assessment issues touched upon in this article in the light of the evaluation of GM stacked events also account for single GM events. For instance, the discussion on the need of information on expression level of traits in a new genetic background is relevant for both single and stacked GM events. In the evaluation of dossiers for the placing of a single GM event on the market, hybrid lines obtained from crosses of a GM line with one or more conventional bred inbred lines are assessed. Via Southern blot analysis it is assessed if the insert remains stable in different genetic backgrounds. Environmental risk assessment studies and food/feed safety assessment studies are conducted on the hybrids to be placed on the market. Therefore, one can say that the evaluation of GM stacked events is different from the assessment of GM hybrids in respect that the combined effects of the transgenes and the effects of the potential interactions between the newly expressed proteins should be assessed.

\section{Acknowledgements}

We would like to thank Gijs Kleter and two anonymous reviewers for their valuable comments on an earlier version of the manuscript.

\section{References}

ACRE (2004). Scientific safety assessment of GM hybrids. Available from http://www.defra.gov.uk/environment/acre/pubs/pdf/efsamaizehybrids-030804.pdf

Ammann, K. (2005). Effects of biotechnology on biodiversity: herbicidetolerant and insect-resistant GM crops. Trends in Biotechnology, 23, 388-394.

BAC (2004). Advice on the reply of Syngenta of 28 July concerning the application Bt11 sweet maize under Regulation (EC) No. 258/97. Available from http://www.bio-council.be/docs/BAC_2004_SC_ 165.pdf

Chapman, M. A., \& Burke, J. M. (2006). Letting the gene out of the bottle: the population genetics of genetically modified crops. New Phytologist, 170, 429-443.

Chassy, B., Hlywka, J. J., Kleter, G. A., Kok, E. J., Kuiper, H. A., McGloughlin, M., et al. (2004). Nutritional and safety assessments of foods and feeds nutritionally improved through biotechnology prepared by a task force of the ILSI International Food Biotechnology Committee. Comprehensive Reviews in Food Science and Food Safety, 3, 35-104.

Clark, J. H., \& Ipharraguerre, I. R. (2001). Livestock performance: feeding biotech crops. Journal of Dairy Science, 84(E. Suppl.), 9-18.

Devos, Y., Reheul, D., \& De Schrijver, A. (2005). The co-existence between transgenic and non-transgenic maize in the European Union: a focus on pollen flow and cross-fertilization. Environmental Biosafety Research, 4, 71-87.

EC (2001). Directive 2001/18/EC of the European Parliament and of the Council of 12 March 2001 on the deliberate release into the environment of genetically modified organisms and repealing Council Directive 90/220/EEC. Official Journal of the European Communities, L106, 1-39, Available from http://eur-lex.europa.eu/JOHtml.do?uri=OJ:L:2001:106:som: en:html

EC (2002). Commission Decision of 24 July 2002 establishing guidance notes supplementing Annex II to Directive 2001/18/EC of the European Parliament and of the Council on the deliberate release into the environment of genetically modified organisms and repealing Council Directive 90/220/EEC. Official Journal of the European Communities, L200, 22-33, Available from http://eur-lex.europa.eu/JOHtml.do?uri=OJ:L:2002:200:som:en: html

EC (2003a). Regulation (EC) No. 1829/2003 of the European Parliament and of the Council of 22 September 2003 on genetically modified food and feed. Official Journal of the European Communities, L268, 1-23, Available from http://eur-lex.europa.eu/ JOHtml.do?uri=OJ:L:2003:268:som:en:html

EC (2003b). Guidance document for the risk assessment of genetically modified plants and derived food and seed. Prepared for the Scientific Steering Committee by the Joint Working Group on Novel Foods and GMOs. http://europa.eu.int/comm/food/fs/sc/ ssc/out327_en.pdf

EC (2006). Commission Decision of 16 January 2006 concerning the placing on the market, in accordance with Directive 2001/18/EC of the European Parliament and the Council, of a maize product (Zea Mays L., hybrid MON863 $\times$ MON810) genetically modified for resistance to corn rootworm and certain lepidopteran pests of maize. Official Journal of the European Communities, L26, 17-19, 
Available from http://eur-lex.europa.eu/JOHtml.do?uri=OJ:L:2006: 026:som:en:html

EFSA (2004). Guidance document of the Scientific Panel on Genetically Modified Organisms for the risk assessment of genetically modified plants and derived food and feed. The EFSA Journal, 99, 1-94, Available from http://www.efsa.europa.eu/en/science/gmo/ gmo_guidance/660.html

EFSA (2005a). Opinion of the Scientific Panel on Genetically Modified Organisms on a request from the Commission related to the notification (Reference C/DE/02/9) for the placing on the market of insect-protected genetically modified maize MON863 $\times$ MON810, for import and processing, under Part C of Directive 2001/18/EC from Monsanto. The EFSA Journal, 251, 1-22, Available from http://www.efsa.europa.eu/en/science/gmo/ gmo_opinions/1030.html

EFSA (2005b). Opinion of the Scientific Panel on Genetically Modified Organisms on an application (Reference EFSA-GMO-DE-2004-03) for the placing on the market of insect-protected genetically modified maize MON863 $\times$ MON810, for food and feed use, under Regulation (EC) No. 1829/2003 from Monsanto. The EFSA Journal, 252, 1-23, Available from http://www.efsa.europa.eu/en/ science/gmo/gmo_opinions/1031.html

EFSA (2005c). Opinion of the Scientific Panel on Genetically Modified Organisms on an application (Reference EFSA-GMO-UK-2004-06) for the placing on the market of insect-protected glyphosatetolerant genetically modified maize MON863 $\times$ NK603, for food and feed uses, and import and processing under Regulation (EC) No. 1829/2003 from Monsanto. The EFSA Journal, 255, 1-21, Available from http://www.efsa.europa.eu/en/science/gmo/ gmo_opinions/1032.html

EFSA (2005d). Opinion of the Scientific Panel on Genetically Modified Organisms on an application (Reference EFSA-GMO-BE-2004-07) for the placing on the market of insect-protected glyphosate-tolerant genetically modified maize MON863 $\times$ MON810 $\times$ NK603, for food and feed uses, and import and processing under Regulation (EC) No. 1829/2003 from Monsanto. The EFSA Journal, 256, 1-25, Available from http://www.efsa.europa.eu/en/science/gmo/ gmo_opinions/1033.html

EFSA (2005e). Opinion of the Scientific Panel on Genetically Modified Organisms related to the application (Reference C/BE/96/01) for the placing on the market of glufosinate-tolerant hybrid oilseed rape Ms8 $\times$ Rf3, derived from genetically modified parental lines (Ms8, Rf3), for import and processing for feed and industrial uses, under Part C of Directive 2001/18/EC from Bayer CropScience. The EFSA Journal, 281, 1-23, Available from http://www.efsa.europa. eu/en/science/gmo/gmo_opinions/1178.html

EFSA (2005f). Opinion of the Scientific Panel on Genetically Modified Organisms on a request from the Commission related to the notification (Reference $\mathrm{C} / \mathrm{GB} / 02 / \mathrm{M} 3 / 3$ ) for the placing on the market of glyphosate-tolerant and insect-resistant genetically modified maize NK603 $\times$ MON810, for import and processing under Part C of Directive 2001/18/EC from Monsanto. The EFSA Journal, 308, 1-22, Available from http://www.efsa.europa.eu/en/science/gmo/ gmo_opinions/1283.html

EFSA (2005g). Opinion of the Scientific Panel on Genetically Modified Organisms on an application (Reference EFSA-GMOUK-2004-01) for the placing on the market of glyphosate-tolerant and insect-resistant genetically modified maize NK603 $\times$ MON810, for food and feed uses under Regulation (EC) No. 1829/2003 from Monsanto. The EFSA Journal, 309, 1-22, Available from http://www.efsa.europa.eu/en/science/gmo/ gmo_opinions/1284.html

EFSA (2006a). Public consultation of the document "Risk assessment of plants containing genetic modification events combined by crossing". Available from http://www.efsa.europa.eu/en/science/ gmo/gmo_consultations/gmo_hybrids_publcons.html. Accessed 06.07.06.
EFSA (2006b). Opinion of the Scientific Panel on Genetically Modified Organisms on an application (Reference EFSA-GMO-UK2004-05) for the placing on the market of insect-protected and glufosinate and glyphosate-tolerant genetically modified maize $1507 \times$ NK603, for food and feed uses, and import and processing under Regulation (EC) No. 1829/2003 from Pioneer HiBred and Mycogen Seeds. The EFSA Journal, 355, 1-23, Available from http://www.efsa.europa.eu/en/science/gmo/gmo_opinions/ 1482.html

Estela, A., Escriche, B., \& Ferre, J. (2004). Interaction of Bacillus thuringiensis toxins with larval midgut binding sites of Helicoverpa armigera (Lepidoptera: Noctuidae). Applied and Environmental Microbiology, 70, 1378-1384.

EuropaBio (2005). Evaluation of crops containing GM events combined by traditional breeding. Available from http://www.europabio. org/relatedinfo/CP12.pdf

Fagard, M., \& Vaucheret, H. (2000). (Trans)gene silencing in plants: how many mechanisms? Annual Review in Plant Physiology and Plant Molecular Biology, 51, 167-194.

FAO/WHO (2006). Report of the fifth session of the codex ad hoc intergovernmental task force on foods derived from biotechnology (ALINORM 06/29/34). Rome: Food and Agricultural Organisation of the United Nations. Available from http://www. codexalimentarius.net

FIFRA (2004). Minutes of FIFRA scientific advisory panel meeting: A set of scientific issues being considered by the U.S. Environmental Protection Agency regarding product characterisation, human health risk, ecological risk and insect resistance management for Bacillus thuringiensis (Bt) cotton products. (Arlington, Virginia). Available from http://www.epa.gov/scipoly/sap/meetings/2004/ june/final1a.pdf

Halpin, C. (2005). Gene stacking in transgenic plants - the challenge for 21 st century plant biotechnology. Plant Biotechnology Journal, 3, 141-155.

Hua, G., Masson, L., Jurat-Fuentes, J. L., Schwab, G., \& Adang, M. J. (2001). Binding analyses of Bacillus thuringiensis Cry $\delta$-endotoxins using brush border membrane vesicles of Ostrinia nubilalis. Applied and Environmental Microbiology, 67, 872-879.

Kuiper, H. A., Kleter, G. A., Noteborn, H. P. J. M., \& Kok, E. J. (2001). Assessment of the food safety issues related to genetically modified foods. Plant Journal, 27, 503-528.

Li, H., Gonzalez-Cabrera, J., Oppert, B., Ferre, J., Higgins, R. A., Bushman, L. L., et al. (2004). Binding analyses of Cry1 Ab and Cry1Ac with membrane vesicles from Bacillus thuringiensisresistant and -susceptible Ostrinia nubilalis. Biochemical and Biophysical Research Communications, 323, 52-57.

OECD (2002). OECD guidance for the designation of a unique identifier for transgenic plants. Series on Harmonization of Regulatory Oversight in Biotechnology, No. 23. Available from http://www.olis.oecd.org/olis/2002doc.nsf/LinkTo/ env-jm-mono(2002)7

Pinçon, G., Chabannes, M., Lapierre, C., Pollet, B., Ruel, K., Joseleau, J.-P., et al. (2001). Simultaneous down-regulation of caffeic/5-hydroxy ferulic acid-O-methyltransferase I and cinnamoylcoenzyme A reductase in the progeny from a cross between tobacco lines homozygous for each transgene. Consequences for plant development and lignin synthesis. Plant Physiology, 126, 145-155.

Schnepf, E., Crickmore, N., Van Rie, J., Lereclus, D., Baum, J., Feitelson, J., et al. (1998). Bacillus thuringiensis and its pesticidal crystal proteins. Microbiology and Molecular Biology Reviews, 62, 775-806.

Snow, A. A., Pilson, D., Rieseberg, L. H., Paulsen, M. J., Pleskac, N., Reagon, M. R., et al. (2003). A Bt transgene reduces herbivory and enhances fecundity in wild sunflowers. Ecological applications, $13,279-286$. 